\title{
RESENHAS
}

RICUPERO, Bernardo. 2004. O romantismo e a idéia de nação no Brasil (1830-1870). São Paulo : M. Fontes.

\section{AMBIGÜIDADES NO ALÉM-MAR: O ROMANTISMO IBÉRICO NO NOVO MUNDO}

\author{
Rosmália Ferreira dos Santos
}

Um mérito que não pode deixar de ser creditado ao livro Romantismo e a idéia de nação no Brasil, de Bernardo Ricupero, é o de ser um empreendimento audacioso. Afinal, não é difícil duvidar, como faz o historiador das idéias Artur Lovejoy, que o romantismo tenha sido, de fato, alguma coisa (Lovejoy apud BERLIN, 1965, p. 19). Suas tendências, influências e características são tão díspares e contraditórias que a indefinição tornou-se a definição mais operante em matéria de romantismo. Todavia, ainda mais audacioso do que admitir que o movimento romântico existiu e teve implicações históricas relevantes é tentar localizar essas influências no campo em que ele apresenta suas mais intricadas aporias: no domínio da política. Parece-me bastante claro que houve um entrelaçamento oportuno entre o romantismo e a política desde os seus primórdios, mas nunca foi muito fácil capturar essa influência, em virtude das próprias complexidade e ambigüidades do movimento. Parece claro, como reconhece o próprio Ricupero no caso da França, que houve diferentes romantismos. E eu diria mais: não apenas houve diferentes romantismos, como mesmo o romantismo alemão, a matriz de todos os romantismos, assentava-se em princípios autocontraditórios. O princípio da individualidade única, a singularidade, por exemplo, um dos pilares do movimento, é inconciliável com o princípio da unidade orgânica entre indivíduo e comunidade, um certo coletivismo, ou comunalismo, que também é uma das bases de sustentação do romantismo. Tudo isso faz da tentativa de apontarem-se as influências do romantismo sobre qualquer processo político uma empresa particularmente arriscada.

É claro que a influência de alguns elementos do romantismo, ou da febre romântica do Ocidente ao longo do século XIX, podem ter favorecido o desenvolvimento de uma idéia de nação na América Latina; é comum que os homens de determinada época ajam de acordo com as referências do seu tempo. O difícil é precisar quais dessas referências podem ser, exclusivamente, creditadas a um romantismo de tendências tão fluidas quanto controversas. Carl Schmitt, por exemplo, aponta uma afinidade natural entre o romantismo, com sua estetização da política, e a ordem liberal. Já para liberais do século XIX, como Stuart Mill e Constant, parecia não haver tanta clareza a respeito dessa naturalidade; pelo menos é o que se denota de seus discursos sobre a liberdade e sobre a necessidade de adequarem-se as instituições políticas do seu tempo às necessidades de um mundo moderno e romântico. Esse otimismo liberal com a modernidade romântica não impediu, todavia, que um parentesco entre romantismo e tendências conservadoras ou totalitárias também fosse aventado; é isso que fez o historiador Isaiah Berlin nos seus primeiros escritos sobre os pensadores alemães do período romântico.

Ainda que Ricupero não tenha explicitado todas estas idiossincrasias do romantismo, seu livro é, de certa forma, “vitimado” por essas ambigüidades do tema com que está lidando.

O livro é composto de três partes mais ou menos independentes. Na primeira temos um preâmbulo com o prefácio de Célia Galvão; uma introdução do próprio autor, fazendo um breve resumo do caráter geral da obra e da apropriação pelos "românticos” brasileiros e latino-americanos das referências intelectuais européias, com o intuito de criar uma identidade nacional para os estados recém-emancipados da colonização ibérica; uma discussão teórico-conceitual sobre a idéia de nação e nacionalismo e uma breve incursão sobre o debate intelectual na França pós-revolucionária. A segunda e a terceira partes tratam especificamente da apropriação por aqueles que Ricupero chama de "românticos brasileiros e argentinos” do ideário romântico para a construção de um projeto político-cultural em seus jovens países.

De modo geral, o livro tem uma linguagem clara, fluida, e demonstra uma erudição extremante competente do autor que nos oferece, ainda, uma vasta quantidade de notas e referências explicativas como guia para a leitura. Ricupero mobiliza uma literatura vastíssima, sendo que sua pesquisa estende-se por diferentes campos das Ciências Sociais, o que converte o livro em uma excelente referência de pesquisa para o estudioso em humanidades. Os objetivos do autor são também enunciados com muita clareza, em diferentes pontos da obra, 
o que não deixa dúvidas no leitor sobre os seus propósitos e as estratégias que utiliza para a demonstração de sua tese.

Sem embargo, não poderíamos deixar de notar que o livro apresenta certas lacunas que se devem, por um lado, à própria complexidade do problema e, por outro, às estratégias escolhidas pelo autor. Dessa forma, Romantismo e a idéia de nação no Brasil não versa imediatamente sobre o romantismo; apresenta algumas ambigüidades sobre a questão da construção de uma nação e o caso do Brasil não ocupa na obra a centralidade sugerida no título. Com relação ao romantismo, ademais das intricadas aporias que apontamos acima, Ricupero não se dedica, em nenhum ponto da obra, ao problema conceitual do mesmo. Ou seja, a pergunta sobre o que realmente foi o romantismo não figura em suas preocupações. E essa não parece ser uma ausência trivial. Ela cobra seu preço ao longo de todo o livro, especialmente quando o autor lida com o caso argentino.

Já na primeira parte do trabalho, em que Ricupero apresenta o romantismo francês como referência para os latino-americanos e faz uma breve incursão no debate intelectual na França durante os primeiros 50 anos que se seguiram à Revolução Francesa, o autor reconhece que houve diferentes romantismos na França ou, pelo menos, um conservador e outro liberal. Todavia, ao relatar as inúmeras querelas que dividia o campo intelectual e político francês entre conservadores, liberais, clássicos, românticos etc., e em que era possível encontrar conservadores românticos, românticos liberais, conservadores e liberais clássicos, o autor não apenas parece supor uma auto-evidência das linhas demarcatórias das posições dos românticos, como nos leva a crer que os próprios franceses possuíam-na e que eram capazes de definir seu próprio romantismo.

Esse cenário de ambigüidades é transposto para a análise da atuação político-intelectual dos latinos no novo mundo. No caso do Brasil a omissão conceitual não chega a ter grande relevância para o desenvolvimento do argumento, devido a um certo matiz germânico em suas referências. Apesar das polêmicas e divergências que se travaram aqui, é possível enxergar um núcleo unificador do romantismo brasileiro em torno da busca pela singularizarão - fortemente presente no romantismo alemão -, favorecida pelas características particulares do país. Assim, a natureza exuberante e exótica, o canto ao índio - àquela altura já afastado da possibilidade de participação ativa na formação cultural do país, dada sua quase dizimação pelo processo de colonização , a manutenção da unidade e do Império e a busca pela construção de uma historiografia nacional funcionaram como elementos nucleadores do romantismo brasileiro. Essa homogeneidade mostrou-se bastante oportuna para uma possível corroboração da tese de Ricupero. De fato, é inegável que certos mitos, como o da miscigenação benéfica e o da unidade nacional, elaborados pelos intelectuais do Instituto Histórico e Geográfico Brasileiro (IHGB), não apenas mantiveram-se como se perpetuaram ao longo de nossa história, embora sofrendo adaptações não desprezíveis. Apesar disso não nos fica totalmente evidente o que havia naqueles intelectuais de romântico, além da importação e adaptação de temas próximos aos românticos alemães.

Com relação aos intelectuais argentinos a questão é bem mais delicada. Apesar da descrição detalhada que Ricupero fornece da atuação política e intelectual da geração de jovens opositores ao regime de Rosas - a nueva generación - e do esforço empregado por ela no sentido de construir um projeto alternativo de Estadonação para a Argentina, é difícil conceber o que, exatamente, fazia românticos esse jovens românticos, como o autor denomina-os. A polêmica entre Alberdi e Sarmiento, por exemplo, revela tamanha divergência entre as propostas e diversidade de matrizes teóricas e ideológicas, que não apenas afasta os contendores do ideário romântico, como os aproxima da ortodoxia liberal e até mesmo da nascente ideologia socialista. É curioso ver Hobbes, Montesquieu e mesmo Tocqueville arrolados entre os românticos, mesmo que junto a eles os argentinos também tenham lido os românticos franceses e a escola de Direito de Savigny. Além disso, em sua preocupação de edificar a nação argentina, os jovens românticos caminham em direção totalmente contrária aos seus confrades europeus, fato que não é negado pelo autor. A contraposição entre civilização e barbárie, por exemplo, sendo a primeira considerada a missão dos jovens românticos implantar no país recém-criado, é impensável nos marcos do ideário romântico original. Esse caminho inexorável em direção às luzes era precisamente o que a Europa romântica tencionava negar no final do século XVIII e ao longo do século XIX. É compreensível que os intelectuais argentinos, no afã de combater o caudilhismo e a ignorância da maior parte da população, almejassem antes alcançar a Ilustração que seguir as inclinações de uma Europa entediada e ávida de novos modismos. O que não é compreensível, nem verossímil, é imputar-lhe um salto que não poderiam ter dado naquele momento. Ou seja, é difícil imaginar, sem que nos sejam fornecidos marcos conceituais precisos - e, tanto mais competente é a descrição de Ricupero, mais isso se torna patente -, o que essa geração de ardorosos ativistas políticos, que não adotou do romantismo nem seu programa nem suas referências exclusivas, tinha, exatamente, de romântica. 
Poder-se-ia dizer em defesa do autor que seu objetivo não foi discorrer sobre o quê o romantismo foi ou pretendeu ser, mas sobre como "os homens e algumas poucas mulheres que começam a ter atuação política e literária na época que se segue à independência da maior parte das antigas colônias ibéricas na América” impuseram-se a tarefa de definir a identidade política e cultural dos seus países (RICUPERO, 2004, p. XIX) e que esses homens e mulheres autodenominaram-se românticos e foram eles quem, deliberadamente, criaram os símbolos de suas identidades nacionais (idem, p. 37). E que o romantismo serviu apenas para conformar um dialeto político-cultural para aqueles jovens que pretendiam realizar a emancipação mental dos seus países, fornecendo-lhes referências para as nações que estavam engajados em criar (idem, p. XXIX). Tudo isso nos diz o próprio autor. Em sua autodefesa, ele não se limita a tais afirmações; demonstra-nos, com muita propriedade, que no anseio de criar referências culturais para as sociedades em que agiam, aqueles intelectuais não se limitaram a criar revistas, escrever romances e antologias, fazer pesquisa historiográfica ou criar receitas interpretativas, mas engajaram-se diretamente na atividade política. Conforme assegura Ricupero, não detinham apenas a pretensão de criar um projeto de nação, mas de serem eles próprios os melhores condutores desse projeto.

Nesse sentido, é perfeitamente compreensível porque Ricupero não persegue um conceito preciso de romantismo. Porém, ainda é permitido indagar qual era a idéia que os atores em questão tinham de romantismo e que justificava sua auto-interpretação como "românticos".

Além disso, há um outro problema, particularmente grave que se apresenta, aqui. Essa presunção, ou essa intenção deliberada dos "românticos" de criar uma nação e o resultado que é apresentado de suas estratégias, não se casam facilmente com a noção de nação que a intuição fornece-nos nem sequer com a que Ricupero apresenta no início do livro.

Já nas primeiras páginas do seu livro, depois de discorrer sobre diferentes abordagens do problema, Ricupero apresenta o que seria seu conceito de nação. Em diferentes formulações, entendemos que nação é um sentimento acerca de laços perenes de pertencimento, compartilhado por uma comunidade politicamente organizada. O intuito da pesquisa de Ricupero foi averiguar se a idéia e os símbolos que os brasileiros têm desse pertencimento consolidou-se no Brasil durante o período de maior influência do romantismo e pelas mãos dos próprios românticos. Tal suposição está sustentada nos conceitos gramscianos de "bloco histórico" e "hegemonia". De acordo com esses conceitos, intelectuais de determinada classe podem assumir o papel de condutores de determinado projeto político e cultural que, ao congregar outras classes nesse projeto, culmina na universalização dos seus valores para toda uma comunidade política. A sugestão parece ser a de que foi isso que ocorreu no Brasil ao longo do II Reinado, em que os escritores românticos brasileiros lideraram o processo de conformação da nossa idéia de nação. Ricupero parece ter poucas dúvidas de que isso de fato ocorreu. "Como vimos", diz ele, "os românticos propuseram um programa de independência literária, criaram uma historiografia nacional, utilizaram o índio como mito-símbolo do país, sugeriram que a mestiçagem diferencia os brasileiros de outros povos, entre outras coisas" (idem, p. 262). E prossegue dizendo que essas referências continuaram a influenciar as gerações de intelectuais que os seguiram, a ponto de confundirem-se com a própria imagem que temos do país; "o que talvez nos pudesse conduzir à conclusão que, de fato, o romantismo criou a identidade nacional brasileira” (idem, p. 261-262). Sugere, porém, que o processo não se completa com os românticos e que demora algum tempo para consolidar-se, uma vez que esses românticos, devido às suas condições históricas objetivas de partícipes e dependentes de uma sociedade escravocrata, estavam ligados ao grupo senhorial que "dependiam do trabalho escravo para garantir o seu sustento". Isso lhes impossibilitou de pensar uma nação em que houvesse lugar para a maior parte da população (idem, p. 265). Ricupero entende que a visão de nação dos românticos, não sendo errônea, é, todavia, parcial e incompleta. Acredita que a força da escravidão no Império era tal que fez que mesmo alguém como José de Alencar, "não diretamente ligado a ela e relativamente independente", confundisse os interesses escravocratas com os interesses da nação (idem, p. 190). Enfim, Ricupero informa que a obra dos românticos pode ser considerada vitoriosa, embora sua literatura verse sobre temas restritos e para leitores não muito numerosos. "Os problemas sobre os quais discutem não dizem, nem podem dizer, respeito à maior parte da população, escravos e homens livres pobres”, aos quais ficou reservada a condição de estrangeiros no seu próprio país (idem, p. 264).

Algumas questões não podem deixar de ocorrer nesse ponto, a primeira delas com respeito à própria conclusão de Ricupero sobre o sucesso dos românticos. Parece haver poucas dúvidas, ao final da narrativa, de que o autor demonstra a importância que os românticos brasileiros tiveram em realizar algumas coisas escreveram livros, criaram uma historiografia nacional etc. Mas parece pouco crível que possam ter criado, a 
partir disso, uma idéia de nação, mesmo que parcial. E mesmo se lhes déssemos esse crédito, admitindo a criaram, a mim ela pareceria mais que parcial; seria inadequada, equivocada, absurda. Se uma nação pode ser definida, como o foi na constituição de 1824, como a associação política de todos os cidadãos brasileiros, é, no mínimo, paradoxal que seus ícones e seu ideário possam ser forjados sem o conhecimento, a participação e, sequer, a consideração da maior parte desses associados. Não seria mais plausível dizer que se algo formou-se naquele período, ficou confinado à cabeça dos românticos e seus parcos leitores? O que parece ter sido confirmado ao longo das páginas de Romantismo e a idéia de nação no Brasil é que os escravos (bem como seus numerosos descendentes no futuro) e os homens livres pobres que não foram admitidos como consortes no projeto dos românticos e não puderam ler os romances de Alencar talvez ficassem admirados de como vieram a aprender suas lições de nacionalismo. Mas, certamente, não foi por obra dos românticos que alguns mitos, como o da miscigenação benéfica, veio a tornar-se a ideologia hegemônica. Uma hipótese mais plausível seria a de que, na impossibilidade de ser ignorado eternamente, o universo dos negros tenha atravessado os terreiros da senzala e alcançado os livros de Gilberto Freire e sua escola. E sabemos, pelo próprio Ricupero, que não era essa a miscigenação sonhada pelos românticos - pelo menos não é a que encontramos em seus romances mais consagrados.

Além disso, alguns dos mitos arrolados pelo autor como prova da influência romântica são absolutamente datados e de universalidade bastante questionável. O índio como símbolo nacional, por exemplo. Basta um breve olhar sobre o senso comum para percebermos que nenhum dos elementos étnicos e culturais do Brasil tornou-se tão ausente, quase insignificante, quanto o indígena, apesar da bem-intencionada tentativa dos modernistas e, certamente, da Funai (Fundação Nacional do Índio), nos últimos tempos. Tampouco parece convincente creditar o silêncio dos românticos sobre a escravidão à "força da escravidão no Império". Não devia ser tão forte assim, visto que em menos de 20 anos após o final do período coberto pela pesquisa de Ricupero havia oficialmente de extinguir-se. E é difícil imaginar que os românticos, homens das letras tanto quanto homens do Império, pudessem ignorar a pressão, cada vez mais intransigente, pelo fim da escravidão, e silenciar sobre uma instituição que, inevitavelmente, haveria de desaparecer dentro muito em breve, a menos que o Brasil romântico pudesse enfrentar os poderosos interesses que se levantavam contra ela do outro lado do Atlântico, o que é menos crível ainda. Parece, assim, bem pouco plausível que o fim da escravidão não estivesse já no horizonte dos nossos românticos e seus leitores. Não foi, certamente, devido a essas "condições objetivas” que o seu projeto de nação saiu parcial e incompleto: pelo menos os interesses da Inglaterra deviam parecer-lhes bem objetivos.

Um exemplo que talvez corrobore o argumento sobre a omissão deliberada dos românticos brasileiros com relação ao tema da escravidão e da incorporação dos escravos e seus descendentes no seu projeto políticocultural é voz dissidente do poeta Castro Alves, cuja ausência nas considerações do autor não parece de todo compreensível. Até onde nos consta, ele também era romântico, também produziu no período e não se calou sobre a questão. Parece estranho que Ricupero, com uma pesquisa tão vasta, erudita e competente, ao falar do silêncio dos românticos sobre o problema dos escravos, não tenha ouvido o eco destes versos: "Senhor Deus dos desgraçados!/Dizei-me vós, Senhor Deus!/Se é loucura... se é verdade/tanto horror perante os céus...” (ALVES, 2005). Pode ter acontecido que a tuberculose e a consciência de que morreria muito em breve, desonerando a responsabilidade dos escravos de sustentá-lo por mais tempo, tenha incitado o jovem poeta a desafiar o projeto de nação dos seus compatriotas românticos e seus senhores, exatamente na sessão comemorativa dos 46 anos da independência com este brado herético: "E existe um povo que a bandeira empresta P'ra cobrir tanta infâmia e cobardia!...”' (ibidem).

Mas, mesmo se fecharmos os ouvidos para as débeis vozes dissidentes e aceitarmos que o projeto "incompleto e parcial” de nação elaborado pelos românticos deveu-se aos constrangimentos estruturais de sua época, com os quais não podiam romper, sob pena de perecerem, chegaremos a conclusões ainda mais paradoxais. Se o único projeto que poderiam ter elaborado era precisamente aquele que estava em consonância com suas condições objetivas, em que se pode dizer que o romantismo, enquanto projeto ideológico específico, tenha contribuído em alguma coisa? Em outras palavras, se, seguindo os passos do romantismo, os intelectuais brasileiros chegaram apenas aonde, de todo modo, poderiam ter chegado, como saber se não o teriam feito sem ele? Uma ideologia, uma doutrina, um projeto político só pode ser dito apoiar algo quando favorece a implementação de suas metas não apenas em condições que lhe é favorável mas também, e principalmente, naquelas que não são. Ricupero mostra algo absolutamente diferente. O que ele descreve é a adaptação de um ideário, até sua completa distorção - caso, por exemplo, da recolocação da dicotomia entre civilização e 
barbárie com supremacia para a primeira -, aos propósitos de uma elite que queria mudar sem sair da moda ou fazer estragos. Foi para cantar a barbárie, ou seja, para recompor a vida nos moldes naturais, espontâneos, comunais, contra os vícios e a esterilidade do racionalismo ilustrado, que os românticos apareceram. Mas, a menos que se estenda o saudosismo romântico até as culturas escravagistas do passado, não se pode dizer que o romantismo apóie, em qualquer de suas vertentes ou versões, um regime de escravidão. O romantismo foi trazido ao mundo - pelo menos era nisso que acreditavam seus idealizadores - exatamente para libertar o homem de todas as amarras da opressão, inclusive aquelas vindas do interior, da alma, do espírito, e não para endossá-las. O movimento romântico foi, como afirmou Isaiah Berlin, a maior revolução já ocorrida na consciência do Ocidente. Se na América ele não serviu para isso, então, não é exagero dizer, não serviu para nada.

O último ponto que gostaria de abordar aqui é com relação à parte em que o autor descreve os feitos dos jovens românticos da Argentina. Embora a atuação dos jovens intelectuais do Prata seja bem mais interessante no sentido de demonstrar uma ação efetiva de liderança intelectual para forjar e implementar um projeto político com valor universal, sendo ele romântico ou não, não me pareceu um contraponto apropriado ao caso brasileiro, visto que os termos de comparação são bastante limitados. Trataram-se de duas iniciativas diferentes, idealizando projetos diferentes, por meio de estratégias diferentes e em realidades distintas. Os argentinos pretenderam estabelecer um projeto de Estado-nação e utilizaram-se para isso de todas as influências que se mostraram disponíveis e úteis, ao passo que os brasileiros, em um Estado consolidado, foram românticos em um sentido mais estrito, pelo menos no campo literário. Que ambos fossem leitores de Hugo, Guizot, Stäel e Tocqueville não era novidade em sociedades que sonhavam transplantar Paris para os trópicos e o francês era a língua oficial dos salões. A diferença é que, talvez, os argentinos tenham lido mais, e melhor, e sido mais bemsucedidos na transplantação que os brasileiros - políticos de cátedra e românticos de gabinete. Não quero, com isso, dizer que a parte sobre o romantismo argentino seja ociosa no livro; ao contrário, penso que o autor não faz jus a ela nos objetivos centrais da pesquisa. A obra pode, e deve, ser percebido como relativa à construção da idéia de nação no subcontinente latino-americano, visto não apenas ser, em boa medida, disso que o livro trata, como a atuação dos argentinos nesse sentido foi importante e relativamente bem-sucedida, conforme demonstra o próprio Ricupero.

Finalmente, gostaria de explicitar que todas essas considerações acerca da auto-representação equivocada, ou dos projetos inadequados ou absurdos dos românticos latino-americanos em sua presunção de forjar uma identidade nacional para seus países recém-independentes não podem, evidentemente, ser estendidas à analise do autor. Elas apensas sugerem que suas conclusões, demasiado otimistas, devem ser ponderadas com cuidado; à luz de um exame mais crítico das condições objetivas que efetivamente se apresentavam aos seus protagonistas, dos eventos que se seguiram e dos marcos teórico-conceituais do movimento que a supunham referir-se.

Quanto à obra em si, é inegável sua importância no sentido de ampliar o debate acadêmico sobre temas políticos para além dos limites do tratamento técnico que por vezes recebe na Ciência Política. O romantismo foi um dos elementos fundadores da modernidade; é, provavelmente, a última das grandes revoluções que definitivamente modificou a face do Ocidente já presenciadas até o momento. Surpreende que os estudiosos da política - exceção feita à obra clássica de Carl Schmitt, O romantismo político - tenham negligenciado esse fato, não se detendo até o momento nas implicações dessa revolução para as formas políticas modernas. Nesse aspecto o livro de Ricupero é, sem sombra de dúvidas, uma grande contribuição para os estudos em teoria política e social.

Rosmália Ferrreira Santos (rhosinha@yahoo.com.br) é Doutoranda em Ciência Política no Instituto Universitário de Pesquisas do Rio de Janeiro (IUPERJ).

\section{REFERÊNCIASBIBLIOGRÁFICAS}

ALVES, C. 2005. O navio negreiro. Disponível em : http://www.projetomemoria.art.br/CastroAlves/. Acesso em:15.ago.2005. 
BEISER, F. C. 1996. The Early Political Writings of the German Romantics. Cambridge : Cambridge University.

BERLIN, I. 1965. The Roots of Romanticism. Edited by Henry Hardy. Washington, D. C. : The National Gallery of Art.

. 1979. Hume and the Sources of German Anti-Rationalism. In : the History of Ideas. Edited by Henry Hardy. New York : Viking . Against the Current : Essays in

MILL, J. S. 1989. On Liberty. In : STEFAN, C. (ed.). On Liberty and Other Writings. Cambridge : Cambridge University.

RICUPERO, B. 2004. O romantismo e a idéia de nação no Brasil (1830-1870). São Paulo : M. Fontes.

SCHMITT, C. 1986. Political Romanticism. Cambridge, Mass. : Massachusetts Institute of Technology. 